\title{
NOTAS INTORMACOES
}

\section{PROMOVENDO SAÚDE ATRAVÉS DA FORMAÇÃO DE RECURSOS HUMANOS: EXPERIÊNCIA DA ESCOLA DE ENFERMAGEM DE RIBEIRÃO PRETO-USP, CENTRO COLABORADOR DA OMS}

\section{INTRODUÇÃO}

A saúde é considerada como um valor devido ao vínculo à vida. Constitui-se um marco jurídico por ser um bem público e, dessa maneira, torna-se um direito de cada cidadão ${ }^{2}$.

Como direito do indivíduo é resultante de vários fatores, tais como: ambiente, condições de vida compatíveis à dignidade humana, organização e utilização de recursos que se transformem em serviços de saúde, decisões individuais de cada família e de cada comunidade em relação à adoção do estilo de vida e utilização de práticas que visem à diminuição dos riscos com o objetivo de preservar e proteger a saúde.

Como direito e bem público, a saúde torna-se responsabilidade de toda a população e do Estado. Dessa forma, tal responsabilidade traduz-se em obrigação do poder público como também um dever de cada indivíduo ${ }^{1}$.

Segundo a Organização Mundial de Saúde (OMS) a saúde tem que ser conseguida, não pode ser imposta; então, a primeira exigência para o alcance da saúde é um comprometimento tanto por parte de pessoas como por parte do governo.

A promoção da saúde consiste de combinação da educação e intervenções legais, fiscais, econômicas, ambientais e organizacionais relacionadas e desenvolvidas para facilitar a aquisição da saúde e prevenção da doença. A educação é pré-requisito essencial em todos os programas de promoção à saúde ${ }^{6}$.
Maria Helena Palucci Marziale * Isabel Amélia Costa Mendes **

A OMS adota a promoção para a saúde com um conceito unificador para aqueles que reconhecem a necessidade de mudança nas maneiras e condições de vida, a fim de promover a saúde. Neste sentido, este conceito engloba todos os fatores que influenciam a saúde. Admite-se que a promoção da saúde é uma atividade inter-setorial, onde não só os serviços médicos tem a responsabilidade de assegurar a saúde, mas também as indústrias, os sindicatos e os profissionais.

A função tradicional da educação para promover a saúde é influenciar as opções individuais de saúde; seu papel mais radical é influenciar a adoção de políticas públicas saudáveis, aumentando a consciência pública dos problemas em questão. Para tanto, uma das estratégias utilizadas é o aumento da consciência crítica através da intervenção educacional, que procura não meramente fazer com que as pessoas pensem nos problemas, mas que examinem criticamente suas vidas, suas circunstâncias e o ambiente em que vivem, para então agirem como uma comunidade e pressionarem os políticos para implementação de políticas mais adequadas.

A educação profissional é um outro campo educacional que contribui para o processo de promoção da saúde. Refere-se à tentativa de influenciar a saúde e outros profissionais. Seu propósito é duplo: o primeiro é persuadir os tomadores de decisão a assumirem em responsabilidade de promover a saúde e o segundo é facilitar a distribuição dos serviços de saúde necessários à comunidade. A educação profissional tem a função

* Professora Doutora do Departamento de Enfermagem Geral e Especializada da Escola de Enfermagem de Ribeirão Preto da Universidade de São Paulo, Centro Colaborador da Organização Mundial da Saúde para o desenvolvimento da pesquisa em enfermagem

** Professora Titular do Departamento de Enfermagem Geral e Especializada da Escola de Enfermagem de Ribeirão Preto da Universidade de São Paulo, Centro Colaborador da Organização Mundial da Saúde para o desenvolvimento da pesquisa em enfermagem 
de aumentar a consciência e oferecer conhecimentos e habilidades imprescindíveis ao profissional da saúde para que se torne e efetivamente atue como provedor e educador de saúde.

O objetivo deste trabalho é particularizar um caso institucional, realçando suas ações que tem sido dirigidas para a promoção de saúde através da formação profissional. Para tanto, situaremos a EERP-USP enquanto Centro Colaborador da OMS para o desenvolvimento da enfermagem e em seguida apresentaremos indicadores demonstrativos do modo pelo qual a referida instituição tem contribuido para o processo de promoção à saúde.

\section{CARACTERIZAÇÃO DA ESCOLA DE ENFERMAGEM DE RIBEIRÃO PRETO COMO CENTRO COLABORADOR DA OMS}

A Escola de Enfermagem de Ribeirão Preto da Universidade de São Paulo (EERP-USP) há 42 anos vem formando recursos humanos para atuarem como educadores de saúde. Tendo em vista o comprometimento do corpo docente para com o desenvolvimento dos postulados de "saúde para todos", a EERP-USP colocou-se à disposição daquele Organismo Internacional em agosto de 1987, para atuar como um Centro de Referência.

Apresentou um projeto de trabalho baseado na formação de recursos humanos em Enfermagem a níveis de graduação e pós-graduação, na educação continuada de profissionais, priorizando a pesquisa, no estabelecimento de mecanismos de intercâmbio regional para contribuição científica através da difusão da informação, assim como na criação e desenvolvimento de núcleos de trabalho voltados para a investigação, ensino e assistência, sintonizados com os programas daquela Organização. Resultou desta iniciativa uma proposta da OMS, datada de 03 de março de 1988, de designação da Escola como Centro Colaborador para o Desenvolvimento da Pesquisa em Enfermagem. Em 1992 foi redesignado para mais um quadriênio ${ }^{5}$.

Um Centro Colaborador é uma instituição designada para participar de uma rede colaborativa internacional, realizando atividades de apoio aos programas daquela Organização em todos os níveis. Contribui ainda para o aumento da cooperação técnica com e entre países, fornecendo-lhes informações, serviços e consultoria, além de estimular e apoiar o treinamento e a pesquisa ${ }^{5}$.

A rede de Centros Colaboradores da OMS representa um mecanismo para que se efetive a cooperação técnica entre este Organismo e os Estados Membros, mecanismo este que tem sido desenvolvido e adaptado às novas exigências programáticas assegurando consistência com as necessidades de cooperação internacional.

Dentre vários Centros da OMS, atualmente 30 são específicos para a área de Enfermagem os quais localizam-se em seis regiões; Região das Américas (11); Região Européia (10); Região do Oriente Médio (1); Região Africana (2); Região do Pacífico Ocidental (4) e Região do Sudeste da Ásia (2).

A caracterização Escola de Enfermagem de Ribeirão Preto da USP como Centro Colaborador está orientada para o Desenvolvimento da Pesquisa em Enfermagem através de oito Termos de Referência, quais sejam:

\section{Termos de ReferênCIA:}

1. Promoção e incentivo à pesquisa em Enfermagem orientada pelos critérios de atenção primária de saúde em diferentes níveis e áreas da prática de Enfermagem: saúde mental, saúde escolar, saúde ocupacional, saúde da mulher, saúde da criança e saúde do idoso, bem como outros programas que beneficiem a comunidade.

2. Facilitação do desenvolvimento de uma massa crítica de enfermeiras pesquisadoras envolvidas em pesquisas em serviços de saúde, especialmente aqueles que são vinculados à tomada de decisões e os que contribuem para uma prática de enfermagem mais eficaz e aprimorada.

3. Apoio ao desenvolvimento de programas de educação continuada para pesquisa em Enfermagem, orientada no sentido de introduzir mudanças nas quais os hospitais sirvam como efetivos pontos de referência e apoio para a atenção primária de saúde.

4. Incentivo e promoção ao intercâmbio de pesquisadores em educação e serviços, assim como instituições.

5. Desenvolvimento de mecanismos para divulgação nacional, regional e internacional dos achados das pesquisas, conforme seja apropriado.

6. Estabelecimento de um centro de recursos bibliográficos mediante integração de uma rede para partilha e distribuição de material de ensino/ aprendizagem para pesquisa em Enfermagem.

7. Desenvolvimento de atividades de pesquisa em Enfermagem em apoio ao programa de trabalho de unidades pertinentes à OMS. 
8. Organização e preparação de reuniões entre estudantes graduandos e formandos para abordar medidas importantes no contexto dos termos de referências.

\section{CONTRIBUINDO PARA O PROCESSO DE PROMOÇÃO À SAÚDE: ESTRATÉGIAS EM AÇ̃̃O}

Com o propósito de formar massa crítica de pessoal de Enfermagem a partir de 1989 foram tomadas medidas a nível de ensino, pesquisa e serviço de extensão visando acentuar os programas já existentes e introduzidas novas vias de formação de pessoal. Passaremos a pontuar alguns deles.

\subsection{Nível de Graduação:}

- Participação no projeto da Pró-Reitoria de Cultura e Extensão da USP denominado "Universidade e Profissões" cujo enfoque está voltado a oferecer orientação aos vestibulandos sobre as profissões a fim de auxiliá-los a uma opção consciente da carreira escolhida.

- Oferecimento anual de 7 vagas destinadas a alunos estrangeiros oriundos do programa Estudante Convênio
Graduação(PEC-G), de responsabilidade compartilhada entre a USP e o Ministério de Relações Exteriores do Brasil. A Escola já recebeu 23 alunos estrangeiros tendo formado até o momento 16 enfermeiros oriundos do Peru, Panamá e Angola.

- Introdução do aluno de graduação em atividades de pesquisa de forma extra curricular integrada ao programa de formação de recursos humanos em pesquisa mantido por agências financiadoras de ciência e tecnologia tais como: Programa Especial de Treinamento - PET/CAPES, Bolsa Trabalho COSEASUSP, Programa de Iniciação Científica do CNPq e da FAPESP, entre outros.

\subsection{Nível de Pós-Graduação}

- Oferecimento de vagas nos programas de PósGraduação, nas áreas; Enfermagem Fundamental (níveis mestrado e doutorado), Enfermagem Psiquiátrica (nível mestrado), Enfermagem em Saúde Pública (nível mestrado) e através do programa Interunidades de Doutoramento em Enfermagem, mantido conjuntamente com a Escola de Enfermagem da Universidade de São Paulo. Os cinco programas visam formar enfermeiros pesquisadores que atuarão como líderes visando a melhoria da prática de Enfermagem e, portanto, a promoção à saúde.

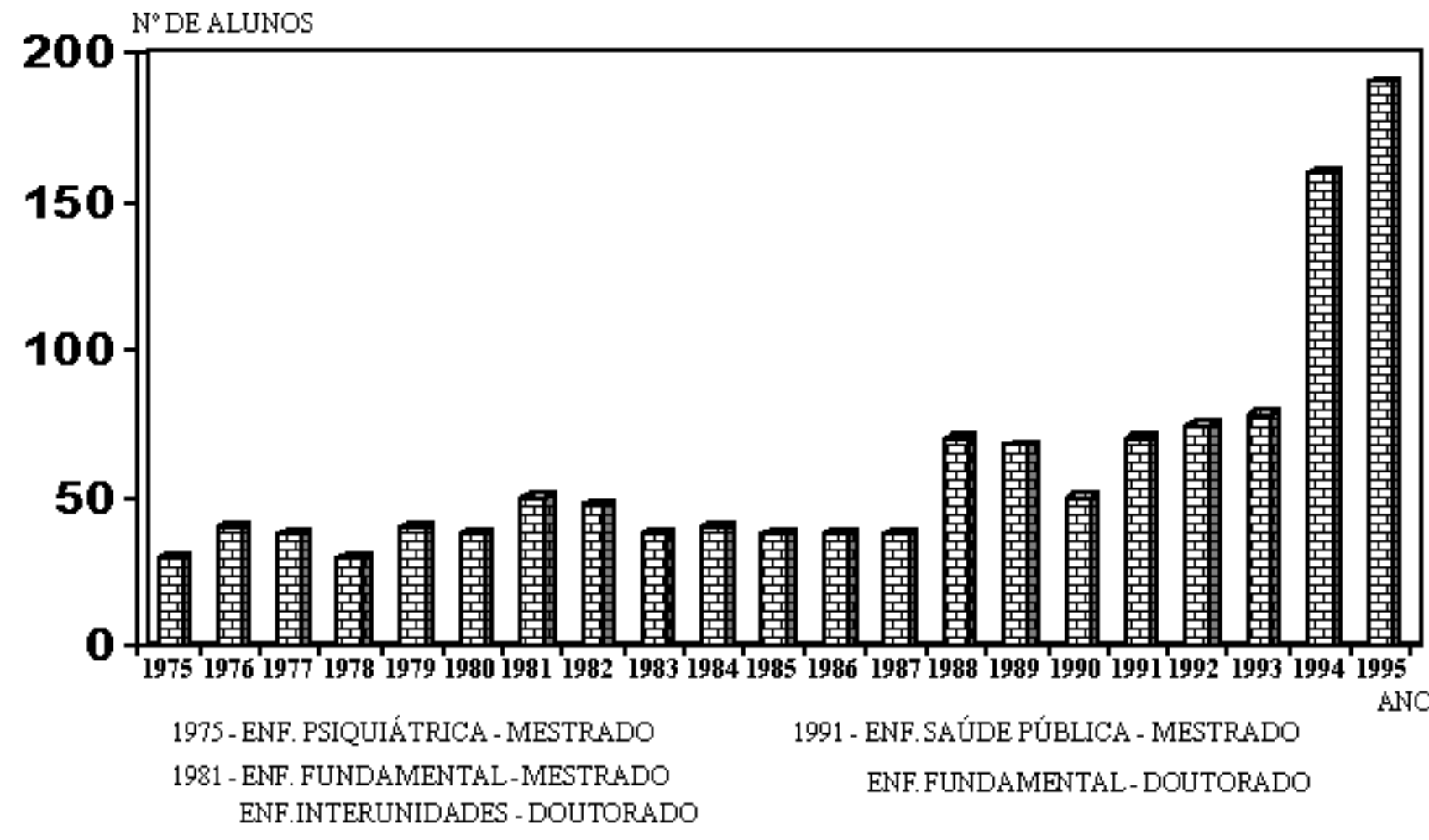

Figura 1 - Alunos regularmente matriculados nos programas de Pós-Graduação da EERP-USP (1975 1995) 
Através da figura 1 verifica-se o número de alunos regularmente matriculados nos programas de pósgraduação da instituição aqui analisada no período de 1975 a 1995. Os dados relativos aos últimos vinte anos demonstram a vitalidade dos programas de pósgraduação desta Escola/Centro em termos de freqüência dos alunos matriculados, de constância na oferta e ocupação das vagas, e especialmente o seu acentuado acréscimo a partir de sua designação como Centro Colaborador. Conforme já mencionado por Mendes ${ }^{4}$, registrou-se neste período duas tendências. Uma delas é a de atendimento preponderante de enfermeirosdocentes de instituições de ensino de diferentes regiões do país, considerando-se apenas os alunos que exercem a docência. A outra tendência é de maior procura pelos cursos de Mestrado por enfermeiros assistênciais ligados a hospitais e unidade básicas de saúde. Acredita-se que o expressivo número de mestrandos provenientes da área assistêncial represente um fator relevante para que, através desta formação, estes profissionais assumam liderança e o poder de decisão nos serviços de saúde para a melhoria da assistência de enfermagem ${ }^{4}$.

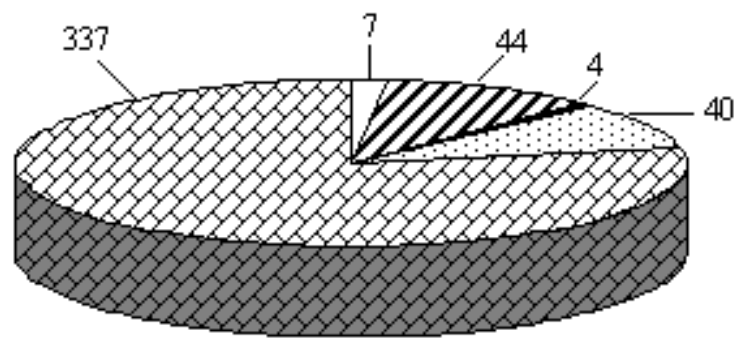

BRASIL - NÚMERO DE ALUNOS POR REGIÄO

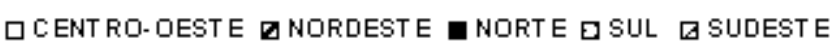

\section{TOTAL - 432 ALUNOS}

Estes dados vem reforçar a atuação deste Centro como polo formador de recursos humanos de enfermagem a nível de pós-graduação, absorvendo cada vez mais profissionais de várias partes do Brasil que atuam em docência e que vem buscar sua formação neste nível, além de exercer influência sobre profissionais de instituições de assistência a saúde, a ponto de ter apresentado uma inversão na demanda dos cursos de Mestrado. A partir de 1988 começou a haver concorrência entre enfermeiros docentes e assistênciais pelas vagas oferecidas. Em 1992, por exemplo, 42,7\% dos alunos selecionados eram ligados à docência à época da matrícula, enquanto 57,3\% atuavam em serviços de saúde. Este novo perfil da demanda indicou a possibilidade de maior alcance do Termo de Referência 2, uma vez que este Centro passou a formar maior contingente de enfermeiros assistênciais aptos a assumirem a liderança e o poder decisório nos serviços de saúde, a promoverem mudanças em seus serviços em prol da promoção à saúde e melhoria da assistência de enfermagem.

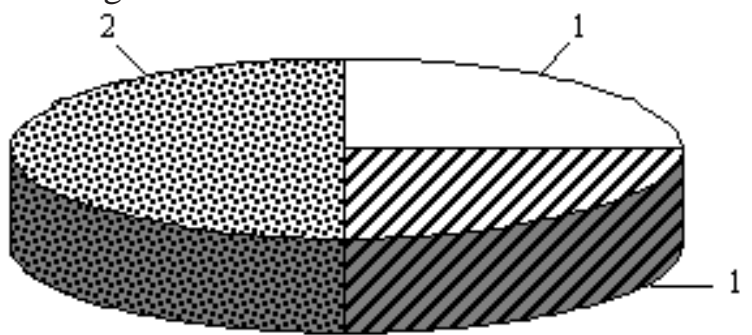

OUTROS PAÍSES - NÚMERO DE ALUNOS POR PAÍS IEUA ÐCOLÔMBIA GINGLATERRA

TOTAL-4ALUNOS

Figura 2 - Naturalidade dos alunos da Pós-Graduação da EERP- 1975 a 1995

Com o aumento do número de pós-graduandos inseridos nos programas, conseqüentemente houve

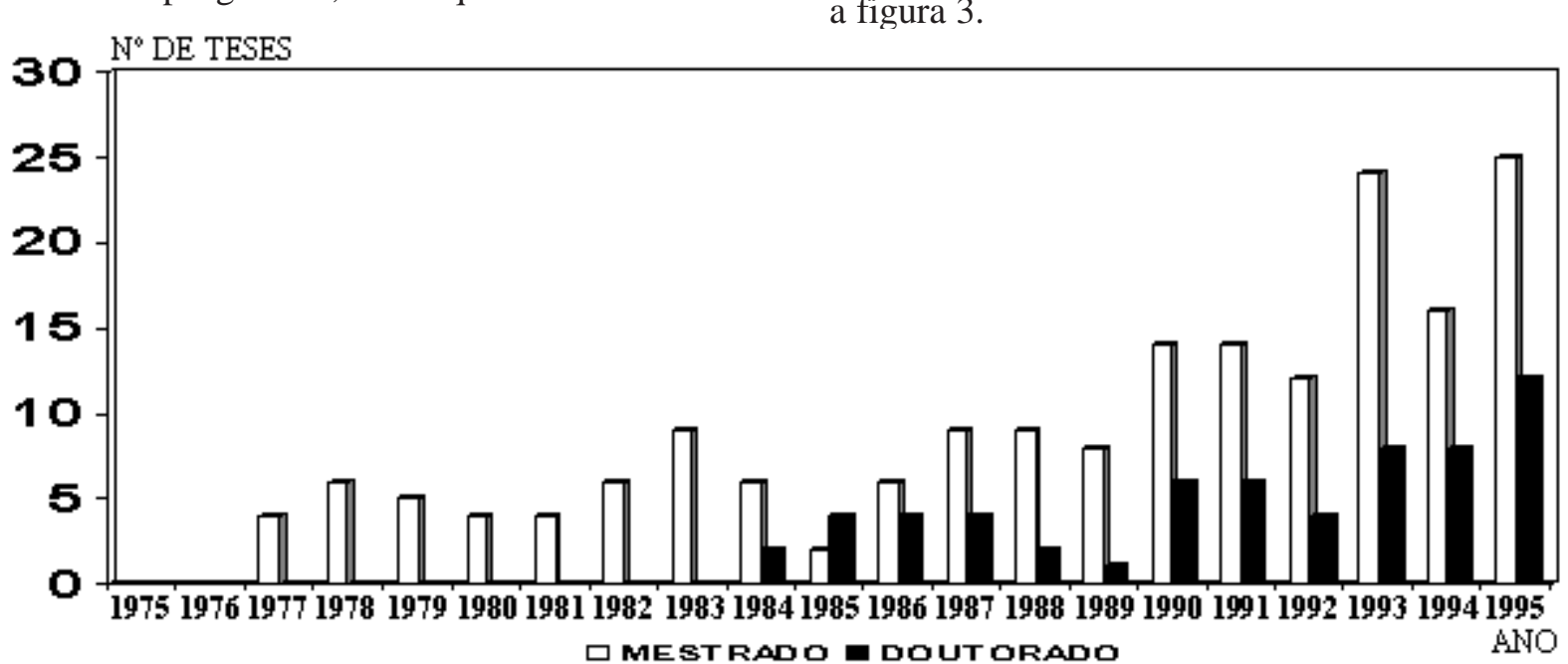

aumento na produção de dissertações e teses especialmente no período de 1989 a 1995, como mostra a figura 3 .

Figura 3 - Produção de dissertações e teses (1975-1995) Escola de Enfermagem de Ribeirão Preto-USP 
A produção de pesquisas em Enfermagem tem se mostrado extremamente necessária pois é através delas que o conhecimento se solidifica propiciando uma prática profissional consistente e eficaz. Com o propósito de favorecer a divulgação do conhecimento, desde 1993 a Escola de Enfermagem de Ribeirão Preto da Universidade de São Paulo conta com um órgão de divulgação: a Revista Latino-Americana de Enfermagem, que destina-se à publicação de pesquisas originais, relatórios de experiências, revisões, atualizações, documentos considerados relevantes no campo de enfermagem, resenhas, resumos de teses e assuntos de interesse geral para os profissionais de enfermagem da América Latina. A criação deste novo veículo demostrou a sensibilidade deste Centro para com a "demanda, traduzida pelo compromisso para com a criação e distribuição da informação, para com a produção e expressão do conhecimento" ${ }^{\text {. }}$.

Esta sensibilidade é nutrida pela convicção de que um veículo desta natureza presta-se à integração dos enfermeiros através do conhecimento, incentiva a pesquisa e seus desdobramentos na prática profissional, subsidia programas de formação de pessoal, de educação continuada e de intercâmbio, instrumentalizando, em última análise, ações de promoção à saúde.

Através da Figura 4 podemos observar as publicações junto a referida revista no período de 1993 a 1995 segundo a origem dos autores.

\section{FREQÜENCIA}
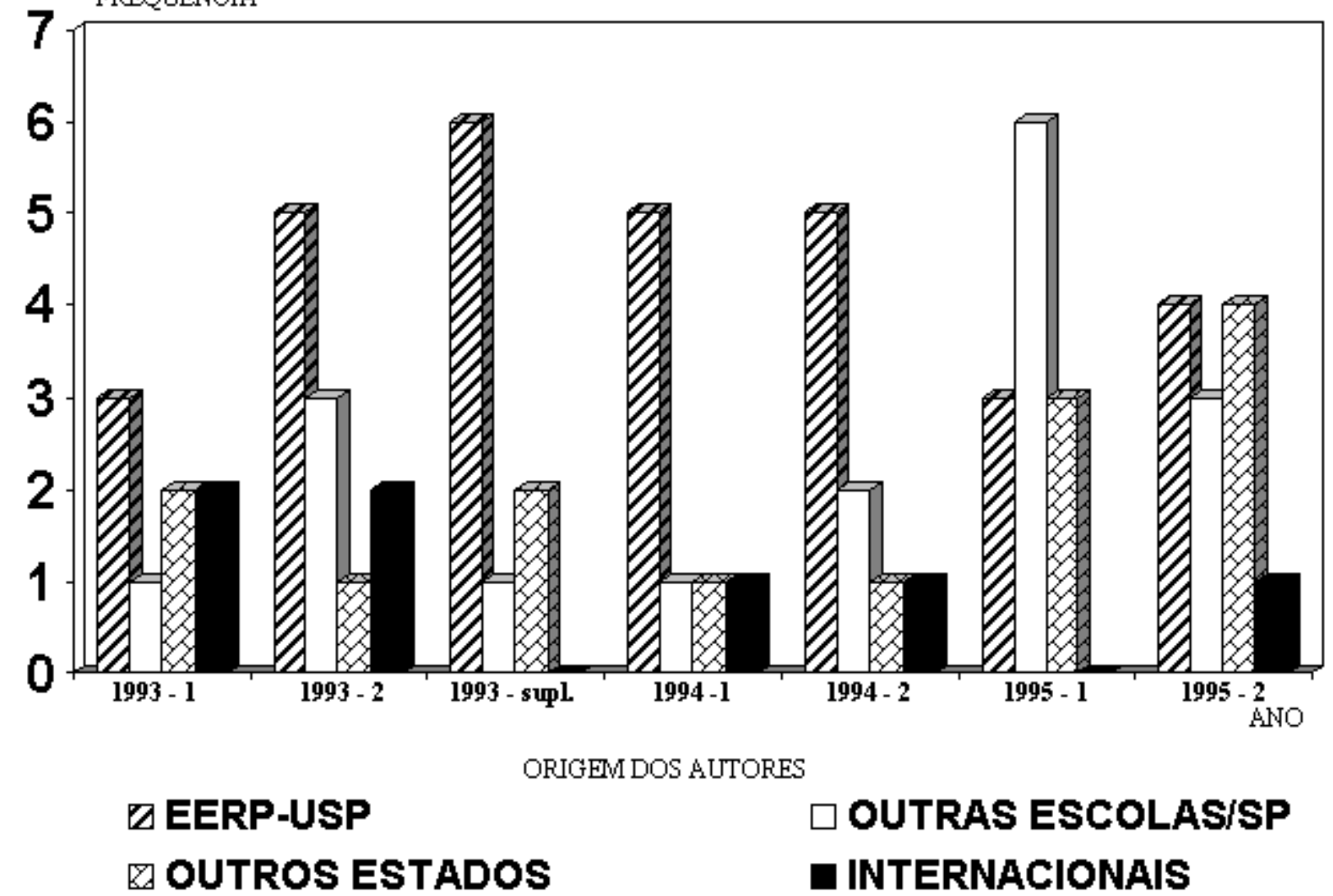

$\square$ OUTRAS ESCOLASISP - INTERNACIONAIS

Figura 4 - Artigos publicados pela Revista Latino-Americana de Enfermagem segundo origem dos autores

Outro instrumento de comunicação com a comunidade de enfermagem também criado com este fim foi o Informativo Latino-Americano de Enfermagem, através do qual a Escola/Centro divulga informações consideradas relevantes para os enfermeiros tais como científicos, resumos de teses de dissertações realizados, opiniões e reflexões sobre temas emergentes na enfermagem, informações sobre atuação de Grupos e Núcleos de Pesquisas, entre outros.

\subsection{Aperfeiçoamento - Pesquisa:}

Oferecimento de programas de treinamento de enfermeiros assistênciais em pesquisa, cujo objetivo é favorecer a formação de uma massa crítica de enfermeiros dedicados à investigação em serviços de saúde. Tais programas são elaborados e conduzidos pelos coordenadores de núcleo e grupos de pesquisa da Escola. 
3.4 Núcleos e grupos de pesquisa e extensão a comunidade:

Articulando os serviços de extensão, pesquisa e ensino de graduação a EERP conta com 26 grupos e núcleos os quais, além do desenvolvimento de investigações científicas, oferecem cursos em diversas modalidades objetivando proporcionar a reciclagem de conhecimentos aos profissionais de enfermagem, cursos, aulas e palestras e atendimento assistêncial à comunidade.

NUESAT - Núcleo de - Desenvolver estudos que visem detectar influência que o trabalho e as condições Estudos de Saúde do sob as quais se desenvolve, tem sobre a saúde dos trabalhadores; contribuir no Trabalhador $\quad$ desenvolvimento de ações que visam a promoção da saúde e prevenção da doença ocupacional.

GIPEDEs - Grupo - Promover estudos relacionados com educação em saúde, num enfoque de Interdisciplinar de Pesquisa interdisciplinaridade, trabalho na área de intersecção saúde-educação.

em Educação em Saúde

NUPEGG - Núcleo de - Desenvolver estudos em grupo multiprofissional sobre o envelhecimento para Pesquisa em Geriatria e subsidiar o ensino, a pesquisa e a assistência ao idoso. Promover o desenvolvimento Gerontologia educacional da enfermagem gerontológica.

NAIDST - Núcleos de AIDS - Promover ações de educação à saúde sobre DST/AIDS à diversos segmentos e Doenças Sexualmente Transmissíveis populacionais e profissionais: prestar assistência aos portadores de HIV/AIDS; implementar pesquisa em DST/AIDS.

NUPESCO - Núcleo de - Realizar estudos avançados em Fisiologia. Teoria do Conhecimento. Métodos e Pesquisa e Estudos em Técnicas de Investigação em Saúde Coletiva; realizar estudos metodológicos em Saúde Saúde Coletiva Coletiva; estudar as práticas de saúde em enfermagem no processo de trabalho.

Grupo de Pesquisa - Aprender como as mulheres de diferentes regiões e culturas respondem e percebem Transcultural na Área Saúde os eventos vivenciados por elas, especialmente aqueles que ameaçam a sua sexualidade. da Mulher

Grupo Saúde da Criança e do Adolescente
- Promover estudos e pesquisas sobre assistência à saúde da criança e do adolescente; estudar a inserção da enfermagem nos programas de assistência à criança e ao adolescente. Programar o ensino de Enfermagem Pediátrica.

NALMA - Núcleo de - Implementar pesquisas sobre aleitamento materno nos seus aspectos biológicos, Aleitamento Materno $\quad$ psicológico, social, histórico e antropológico, bem como em relação a tecnologia apropriada a esta área; preparar profissionais que atuam no campo para pesquisar na área; promover seminários e atividades afins para debater a questão da amamentação; criar mecanismos de articulação institucional e interprofissional.

OPE - Oficina de Projetos - Treinar recursos humanos e padronizar o ensino da medida indireta da pressão arterial: em Esfigmomanometria detectar e controlar valores da pressão arterial elevados e divulgar fatores de risco e prevenção da doença hipertensiva e cardiovascular em diferentes segmentos da comunidade.

NUPETICA - ENSAME Núcleo de Ética em - Investigar temáticas específicas ou relacionadas a ética, súde mental e educação em Enfermagem, Saúde Mental e Educação 


\begin{tabular}{|c|c|}
\hline $\begin{array}{l}\text { PROASE - Programa de } \\
\text { Assistência Primária à } \\
\text { Saúde do Escolar }\end{array}$ & $\begin{array}{l}\text { - Promover a atenção integral à saúde do escolar, compreendendo ações de promoção, } \\
\text { preservação e recuperação; analisar como processo de trabalho em saúde na assistência } \\
\text { ao escolar, estendendo-se como assistência à saúde mediada pelo setor educação, } \\
\text { abrangendo do pré-escolar ao adolescente, incluindo a criança de rua. }\end{array}$ \\
\hline $\begin{array}{l}\text { REMA - Núcleo de Ensino, } \\
\text { Pesquisa e Assistência na } \\
\text { Reabilitação de } \\
\text { Mastectomizadas }\end{array}$ & $\begin{array}{l}\text { - Identificar estratégias de assistência integral à mulher com câncer de mama e seus } \\
\text { familiares, estimulando a busca de um maior desempenho de seus papéis e habilidades } \\
\text { dentro de seu contexto social. }\end{array}$ \\
\hline $\begin{array}{l}\text { GACC - Grupo de Apoio à } \\
\text { Criança com Câncer }\end{array}$ & $\begin{array}{l}\text { - Estudo multiprofissional do câncer infantil, tendo em vista a melhoria da qualidade } \\
\text { da assistência. }\end{array}$ \\
\hline $\begin{array}{l}\text { GEPECOPEN - Grupo de } \\
\text { Pesquisa em Comunicação } \\
\text { no Processo de Enfermagem }\end{array}$ & $\begin{array}{l}\text { - Investigar a comunicação no processo de enfermagem em âmbitos interpessoal, } \\
\text { grupal, de massa, institucional e de investigação. }\end{array}$ \\
\hline $\begin{array}{l}\text { Grupo de Investigação em } \\
\text { Recursos Humanos }\end{array}$ & $\begin{array}{l}\text { - Estudar a população que procura os cursos de graduação em enfermagem; } \\
\text { problemática da baixa demanda e as condições do mercado de trabalho/órgão } \\
\text { formadores. }\end{array}$ \\
\hline $\begin{array}{l}\text { G A R P O } \\
\text { LARINGECTOMIZADOS } \\
\text { - Grupo de Apoio e } \\
\text { Reabilitação aos Pacientes } \\
\text { Ostomizados } \\
\text { Laringectomizados }\end{array}$ & $\begin{array}{l}\text { - Investigar os problemas bio-psico-sociais envolvidos no processo de reabilitação do } \\
\text { paciente laringectomizado e desenvolver o ensino desses pacientes. }\end{array}$ \\
\hline $\begin{array}{l}\text { GICOENPA - Grupo de } \\
\text { Investigaçãor sobre } \\
\text { Comunicação Enfermeiro- } \\
\text { Paciente }\end{array}$ & $\begin{array}{l}\text { - Propor instrumentos metodológicos concernentes às pesquisas sobre comunicação } \\
\text { verbal em enfermagem, testar emprego de habilidades comunicativas por enfermeiros } \\
\text { e alunos de enfermagem quando em interação entre si com pacientes. }\end{array}$ \\
\hline $\begin{array}{l}\text { GEPURHEN - Grupo de } \\
\text { Estudos e Pesquisas em } \\
\text { utilização de Recursos } \\
\text { Humanos em Enfermagem }\end{array}$ & $\begin{array}{l}\text { - Analisar as forças propiciatórias da burocratização do trabalho do enfermeiro; } \\
\text { disfunções do trabalho em enfermagem; estabelecer tendências, estratégias e analisar } \\
\text { e promover liderança da enfermagem. }\end{array}$ \\
\hline $\begin{array}{l}\text { Grupo de trabalho/pesquisa } \\
\text { de gerenciamento e } \\
\text { Informática na rede básica } \\
\text { de saúde de Ribeirão Preto }\end{array}$ & $\begin{array}{l}\text { - Assessorar a implantação de gerência e informática nas UBS; subsidiar tecnicamente } \\
\text { as atividades de gerenciamento de informática na Secretaria Municipal de Saúde; } \\
\text { contribuir para a formação e desenvolvimento de recursos humanos em gerenciamento } \\
\text { e informática; implementar e contribuir para o desenvolvimento de pesquisas na área } \\
\text { de gerência, informática e educação continuada; subsidiar e colaborar no } \\
\text { acompanhamento e avaliação das atividades de gerenciamento e informatização. }\end{array}$ \\
\hline $\begin{array}{l}\text { Grupo de estudos em } \\
\text { enfermagem psiquiátrica e } \\
\text { saúde mental }\end{array}$ & $\begin{array}{l}\text { - Criar um espaço para o estudo dessa especialidade, nos aspectos de políticas de } \\
\text { saúde mental e mais especificamente nas questões ligadas à desinstitucionalização; } \\
\text { trocar experiências no âmbito da docência, pesquisa e extensão. }\end{array}$ \\
\hline $\begin{array}{l}\text { GERES - Grupo de Estudos } \\
\text { das Representações Sociais }\end{array}$ & $\begin{array}{l}\text { - Analisar e discutir trabalhos desenvolvidos na área da saúde subsidiados na Teoria } \\
\text { das Representações Sociais; desenvolver projetos de pesquisa afins. }\end{array}$ \\
\hline
\end{tabular}




\begin{tabular}{|c|c|}
\hline $\begin{array}{l}\text { GEMAEn - Grupo de } \\
\text { Estudo em Metodologia da } \\
\text { Assistência de Enfermagem }\end{array}$ & $\begin{array}{l}\text { - Elaborar e testar instrumentos para coleta de dados, diagnóstico, planejamento, } \\
\text { implementação e avaliação à luz dos diferentes modelos teóricos de Enfermagem; } \\
\text { identificar e selecionar estratégias nas situações de assistência, considerando seus } \\
\text { fatores promotores e oponentes. }\end{array}$ \\
\hline $\begin{array}{l}\text { Enfermagem em Urgências } \\
\text { Psiquiátricas }\end{array}$ & $\begin{array}{l}\text { - Avaliar a magnitude dos problemas de saúde mental da região de Ribeirão Preto a } \\
\text { partir de uma fonte de dados (Unidade de Emergência HC, setor de urgências } \\
\text { psiquiátricas). Estão sendo levantados os transtornos psiquiátricos da população } \\
\text { assistida no período de } 1988 \text { a 1993, bem como os principais dados demográficos. Há } \\
2 \text { subprojetos, um investigando os transtornos relacionados ao álcool e o outro os } \\
\text { transtornos e intercorrências psiquiátricas entre a população de adolescentes. O estudo } \\
\text { visa adequar a assistência e o ensino às necessidades da população regional. }\end{array}$ \\
\hline $\begin{array}{l}\text { Programa Educativo de } \\
\text { Saúde do Adulto com } \\
\text { enfoque na Promoção da } \\
\text { Saúde }\end{array}$ & $\begin{array}{l}\text { - Implantar junto à Secretaria Municipal da Saúde um programa de atividades físicas, } \\
\text { recreação e educação em saúde para o adulto, nas UBS. A finalidade é contribuir à } \\
\text { nível de Secretaria da Saúde para a ampliação das funções da UBS em direção à } \\
\text { estratégia de promoção da saúde. }\end{array}$ \\
\hline $\begin{array}{l}\text { Educação para a saúde } \\
\text { integral e orientação sexual/ } \\
\text { sexualidade - DST-AIDS, } \\
\text { drogas e sexo seguro. } \\
\text { (CAESOS - Centro } \\
\text { Avançado de Educação para } \\
\text { a Saúde e Orientação } \\
\text { Sexual/Sexualidade, DST, } \\
\text { AIDS e Droga) }\end{array}$ & $\begin{array}{l}\text { - Investigar escolares de primeiro e segundo graus e universitários procurando levantar } \\
\text { necessidades nesse sentido, planejando, executando e avaliando ações educativas sobre } \\
\text { tais assuntos, bem como intervindo nas ações, se necessário. }\end{array}$ \\
\hline $\begin{array}{l}\text { Pesquisa e ensino das } \\
\text { relações interpessoais em } \\
\text { enfermagem - humanização } \\
\text { da assistência (NUPRI) }\end{array}$ & $\begin{array}{l}\text { - Buscar conhecimentos sobre a humanização da assisência à pessoa que precisa de } \\
\text { ajuda, pesquisar situações que corroborem a importância das relações interpessoais } \\
\text { terapêuticas; propor metodologias que permitam pesquisar as relações interpessoais. }\end{array}$ \\
\hline
\end{tabular}

\subsection{Educação Continuada}

Outra estratégia empregada para promover aprimoramento dos profissionais de enfermagem se dá através da educação continuada.

A Escola de Enfermagem de Ribeirão Preto da Universidade de São Paulo ofereceu no período de 19891995 um total de 153 cursos correspondendo a 6643 horas de atividades destinadas a educação continuada abrangendo a clientela de 4068 enfermeiros.

\subsection{Intercâmbio}

Uma outra atribuição deste centro é incentivar e promover intercâmbio nas áreas de ensino, de serviço e entre instituições, o que tem sido operacionalizado através de visitas técnicas efetuadas por docentes no país e no exterior, visitas recebidas do país e do exterior, assessorias realizadas e constituição de núcleos e grupos de pesquisas.

\section{CONSIDERAÇÕES FINAIS}

Procuramos traçar um breve esboço de seis ações estratégicas institucionais, vinculadas especialmente à formação de recursos humanos em enfermagem, tendo como propósito precípuo de contribuir para com a promoção da saúde. Para o alcance dos resultados e dos indicadores aqui apontados tem sido essencial o comprometimento intelectual, social, emocional e profissional dos integrantes desta instituição, comprometimento este que tem garantido a consistência e a constância das ações de formação de recursos humanos, tendo sempre em perspectiva a meta de promover saúde. 


\section{REFERÊNCIAS BIBLIOGRÁFICAS}

01. LESCURA, Y.; MAMEDE, M.V. Educação em Saúde: abordagem para o enfermeiro. São Paulo: Sarvier, 1990.

02. MACEDO, C.G. Discurso pronunciado na cerimônia de abertura. In. $8^{\text {a }}$ Conferência Nacional de Saúde, Anais. Brasília, Ministério da Saúde, 1986.

03. MENDES, I.A.C.; GIR, E.; TREVIZAN, M.A. Escola de Enfermagem de Ribeirão Preto da Universidade de São Paulo: Centro Colaborador da Organização Mundial da Saúde. Rev. LatinoAm. Enfermagem, Ribeirão Preto. v.1, $\mathrm{n}^{\circ}$ especial, p.53-68 dez. 1993.
04. TONES, K.; TILFORD, S.; ROBINSON, Y.K. Health Education: Effectiveness and efficiency, London: Chapman \& Hall, 1991.

05. WORLD HEALTH ORGANIZATION Who Collaborating Centers: general information. Geneva: WHO, 1987. p.12-3.

06. MENDES, I.A.C. Universidade de São Paulo Escola de Enfermagem de Ribeirão Preto/Centro Colaborador OMS para o desenvolvimento de pesquisa em enfermagem. Relatório Anual. fevereiro 1993. Ribeirão Preto, EERP/USP. 43p.

07. MENDES, I.A.C. Carta ao Leitor. Rev. Latino-Am. Enfermagem, Ribeirão Preto, v. 1 n. 1, p. 7-8, janeiro 1993.

\section{SEMINÁRIO BINACIONAL UNIVERSIDADE FEDERAL DO ACRE E UNIVERSIDAD AMAZÔNICA DE PANDO - ALCANÇA PLENO ÊXITO}

O Seminário Binacional de Ensino, Pesquisa e Extensão nas Áreas de Biologia, Enfermagem, Pedagogia e Informática, promovido pela Universidade Federal do Acre e Universidad Amazônica de Pando, realizado na cidade de Cobija - Bolívia, e desenvolvido no período de 07 a 09.05.97 foi coroado de pleno êxito tendo em vista a excelente programação, organização e freqüência num total de 191 participantes envolvendo brasileiros de Rio Branco, Brasiléia e Epitaciolândia e Bolivianos de Cobija. Outro ponto relevante foi a troca de experiência nas apresentações, distribuição de material didático-técnico e científico, além das visitas e discussões entre os integrantes dos respectivos cursos/ departamentos/direção das instituições envolvidas Destacamos também a receptividade, repercussão na comunidade acadêmica, bem como as atividades sociais. Cabe ainda mencionar o interesse entre as partes de realizar um novo seminário na Universidade Federal do Acre, para o próximo ano. Como ponto culminante o Reitor da Universidad Amazônica de Pando deverá visitar a Universidade Federal do Acre; os departamentos, coordenações e DERCA se comprometeram em analisar e comparar as grades curriculares já pensando na revalidação dos diplomas, bem como estabelecer protocolos de integração com o aproveitamento de docentes de ambas as partes. 